\title{
EFFECT OF CLIMATE UPON CHICKENS
}

\author{
(Letters to the Editor)
}

There are reproduced herewith excerpts from two letters which should be of interest to poultry producers. The writers of these letters or the Editor will welcome any observations which any of its readers might be able to contribute.

The following is taken from a letter written by Dr. O. B. Kent, Director, Feed Research, The Quaker Oats Co., Chicago, Ill., U. S. A. to Dr. F. M. Fronda, Professor of Poultry Husbandry, University of the Philippines, College of Agriculture, Laguna, P. I.

"Poultry raising in the tropics is unquestionably somewhat different than it is in the moderate latitudes. I found shortly after I went with The Quaker Oats Company that our poultry nutrition problems in Miami, Florida were quite different than those in New York and New England-that there we had to have everything in the feed while in the North quite frequently birds could get a good deal from the soil or from grass range. In Miami we have moderately high temperatures eight to ten months of the year. I have an idea their temperatures are probably higher than your temperatures in the Philippines because they do not get the effect of as much cold water around them because they are very close to the warm Gulf current.

In Florida our big problem has been worms; that where chickens are fed on the usual method there has been a tendency for them to become badly infested with tape worms and with the poor soil unless the feed was adequately fortified there were lots of round worms. That condition was so bad when I came with the Company the poultrymen in Florida didn't consider it was worth while to raise chickens in Florida. Pretty nearly all the better poultrymen imported their chickens from the North as ready to lay pullets. They had lots of trouble with them because of colds and other things the birds picked up in transit but even so they were better than what was raised in Florida. Consequently I think their problem was probably very similar though undoubtedly not identical with yours in the Philippines.

Frankly we haven't found any difference in breeds as between Miami or for that matter Cuba and Puerto Rico and northern Canada; both Leghorns and production Reds and Barred Rocks do well in any one of the locations. Probably Leghorns and Reds-or maybe I should say Reds do best in any of the locations. Reds do not put on fat as readily as either Leghorns or Barred Rocks. For that reason they are typically not a particularly good meat bird but are a very excellent bird from the standpoint of egg production, livability and hatchability.

I feel very confident if you will use a system of restricted feeding after your chicks are eight to ten weeks old you really won't have any trouble with tape worms, and if you can get a high grade alfalfa meal and a bunch of greens for your baby chicks, you can go a long way toward holding down round worms in your chicks.

You probably have a copy of the World's Poultry Congress report at Cleveland in 1939 in which Dr. Ackert brought out the fact that quality of proteins and the quantity of vitamin A largely determined the size and number of round worms in chickens. Our field observations would check that very well. In other words, I frankly think your problems are not from the standpoint of breed but are rather from the standpoint of your nutrition. You may have been using entirely too much corn and giving your birds entirely too much feed. Both are extremely bad in warm climates. Chickens can stand quite a lot of corn in the 
North but just don't do well on it in the South. I am very curious to know just what you have been feeding your young chicks, your growing birds and your laying birds, and what feed ingredients you have available in the Philippines. It might be there is a combination you could work out that would do an excellent job.

The following is taken from Dr. Fronda's reply to Dr. Kent:

"I have received your very interesting letter. Indeed, poultry raising in this country is very much different from that of the United States. It took me several years of failure to realize that this is so after I returned from Cornell in 1922. I had thought then that I could bodily transplant here all that I observed in my travels in the United States.

You may be right in your opinion that our problems may not be from the standpoint of breed, but rather from the standpoint of nutrition. This, as we have also observed, is particularly so as far as worms are concerned. In the early days of our work here, we noticed that a large portion of the deaths among our growing stock was due not only to tape worms but also to round worms. After our feeding system had been adjusted, our troubles with worms had been reduced to nil. Before we had modified our rations and had changed our feeding system, mortality caused by worm infestation, although high, was limited during the first eight weeks of the chicken's life; there was hardly any mortality from this cause after this age.

Again, as you have stated, it may also be possible that we are giving our chickens a little too much feed. This, I think, will be worth while studying under our conditions. Experiments with rats have indicated that caloric undernutrition results in a lower incidence of induced malignancies (perhaps may be considered as parallel to parasitic infestations.) Doubtless too, body temperature regulations can be an extra work for an animal with a high caloric intake. McCay, et al have also demonstrated, with rats, promotion of longevity by moderate caloric restriction.

The results of our observations with growing chicks show that it needs about $5.5 \mathrm{lbs}$. of feed to raise a chick to three months of age. With layers producing from 130 to $160 \mathrm{eggs}$, the amount necessary to feed them for a year amounts to about 65 to 70 lbs. Our rations consist mostly of rice by-products, these being the most readily available in this country. Our standard chick ration is composed of 55 parts, by weight, of rice bran, 20 of ground corn, 20 of shrimp meal, and 5 parts of coconut meal. Our laying rations consist of the same ingredients with, of course, different proportions. Are our chickens eating too much of this feed? It would be interesting to find out whether or not a more regulated feeding schedule would be more beneficial than our present system of self-feeding.

You probably have heard that the Philippine Government imported 100,000 chicks last year. With these chicks came enough growing feeds to last them for three months. We took this opportunity to see how our growing ration compares with this imported one and to our surprise, our ration produced much better results than the imported one. This is, indeed, a revelation to us, considering how limited our source of feeds is. We will publish our results of this study as soon as it is completed. By the way, we have developed our standard ration through years of study, using different combinations of the available ingredients.

We too have made some interesting studies regarding breeds. Years before I was sent to Cornell and up to the present time, the Philippine Government has been importing improved breeds of poultry from the United States. The results in all had been invariably the same. The birds were apparently all right during their first year, and they gradually degenerated during the following years. It was very difficult to raise chickens from them. About that time too, some buff birds of no 
definite breeding were imported from southern China, around Canton. We improved these chickens and developed them into excellent fowls that are now popularly known as the Los Banos Cantonese. A few years before the outbreak of the War, Lingnan University in Canton bought breeding stock of this breed from us for multiplication and distribution in that part of China, and recently, we have received an urgent request for the same fowls to rehabilitate the flock of the University that had been looted during the occupation years. This breed has been imported also into Siam and Guam where, according to reports, the fowl is doing well. For general farm flocks, this breed excelled all the others that had been introduced into the Philippines. The birds grew and multiplied and improved under conditions where the other imported breeds have failed even to maintain themselves. Unfortunately, we lost our entire selected breeding stock of this breed. We are now multiplying for selection and breeding work some birds of ordinary stock that we were able to get somewhere after the liberation.

In our efforts to look for an explanation for this behavior of the temperate animals imported into the Philippines, we studied the hemoglobin content of the blood. Among cattle, we found that the hemoglobin of the blood of temperate animals was much lower than that of our own animals or of those imported from other tropical countries, like India. This is not so, however, with chickens. In addition to our hemoglobin studies in chickens, we made blood counts. Our studies of comparative blood counts were just completed when the War broke out, but our data were burned before we had an opportunity to publish them. From these studies, we learned that, when compared with the Cantonese, both the S. C. White Leghorns and the Rhode Island Reds failed to adjust their blood picture according to changes in the weather. The number of erythrocytes of the Cantonese fowls fluctuated according to atmospheric temperature changes, whereas those of the Rhode Island Reds and the S. C. White Leghorns remained the same throughout the twelve months of the year. Apparently, these two breeds are not able to adjust their physiological mechanisms, and they show it particularly during the continuous warm days when you see them panting, even under a cool shade. It is too bad that our data were destroyed, but we are again repeating the same studies. In the present observations, we are using the chickens that we were able to raise from those that we have imported last year.

I have written at length on this subject, but it is one that has seemed most important to me. May I hear from you again about this? There may be other angles that we have not yet touched. It may be possible also that there may be other investigators who have worked along this line. Would you consider publishing excerpts of the letters so as to reach as many parties as possible? It will be doing us a great service by helping us solve a problem that is vital to the poultry industry of the Philippines.

\section{NOTICE TO MEMBERS OF THE WORLD'S POULTRY SCIENCE ASSOCIATION}

The membership subscriptions for 1947 are now due. Many have responded to the Secretary's call for the same. However, there are still some who have not paid. Please remit $\$ 5.00$ or one Pound to the Secretary-Treasurer, Dr. Gustave F. Heuser, Cornell University, Ithaca, N. Y., U. S. A. or to the Assistant Secretary-Treasurer, Major Ian Macdougall, O.B.E., 45 Bedford Sq., London, W.C.1, England. Early remittance will be appreciated. 